\title{
Chronic Exposure to 4-Nonylphenol Alters UDP-Glycosyltransferase and Sulfotransferase Clearance of Steroids in the Hard Coral, Pocillopora damicornis
}

\author{
Luc R. A. Rougée ${ }^{1,2}$, Abby C. Collier ${ }^{1,3}$ and Robert H. Richmond ${ }^{2 *}$
}

${ }^{1}$ Department of Tropical Medicine, Medical Microbiology and Pharmacology, John A. Burns School of Medicine, University of Hawaii, Honolulu, HI, United States, ${ }^{2}$ Kewalo Marine Laboratory, University of Hawaii at Manoa, Honolulu, HI, United States, ${ }^{3}$ Faculty of Pharmaceutical Sciences, The University of British Columbia, Vancouver, BC, Canada

\section{OPEN ACCESS}

Edited by:

Thomas Van Leeuwen, Ghent University, Belgium

Reviewed by: Ali R. Bandani,

University of Tehran, Iran Tomas Erban,

Crop Research Institute (CRI), Czechia

*Correspondence: Robert H. Richmond

richmond@hawaii.edu

Specialty section: This article was submitted to Invertebrate Physiology, a section of the journal Frontiers in Physiology

Received: 18 September 2020 Accepted: 25 January 2021 Published: 17 February 2021

Citation: Rougée LRA, Collier AC and Richmond RH (2021) Chronic Exposure to 4-Nonylphenol Alters UDP-Glycosyltransferase and Sulfotransferase Clearance of Steroids in the Hard Coral, Pocillopora damicornis.

Front. Physiol. 12:608056. doi: 10.3389/fphys.2021.608056
The effects of the xenoestrogen 4-nonylphenol (4NP) on endocrine and metabolic homeostasis in the reef building coral, Pocillopora damicornis were investigated. The aim was to understand if ubiquitous nonylphenol ethoxylate contaminants in the marine environment result in altered homeostatic function. Coral colonies were chronically exposed (6 weeks) to a sublethal concentration (1 ppb) of 4NP and sampled over the coral's lunar reproductive cycle. Although activity of steroidogenic enzymes [cytochrome P450 (CYP) 17, CYP 19, and 3- $\beta$-Hydroxysteroid dehydrogenase] and the conjugation enzyme glutathione-S-transferase was not altered, significant increases in the activity of the steroid clearing enzyme UDP-glycosyltransferase (UGT) were observed. The natural fluctuation of UGT activity with the lunar cycle was replaced with consistently high UGT activity throughout the reproductive cycle during 4NP exposure. No effect of 4NP on the reverse reaction, mediated by $\beta$-glucuronidase, was observed. Thus, 4NP shifts the UGT: $\beta$ glucuronidase ratio toward greater clearance at points in the lunar cycle where retention of compounds is typically favored. Additionally, 4NP reduced activity of the steroid regeneration enzyme steroid sulfatase, further shifting the system toward clearance rather than regeneration. These data imply that environmentally relevant levels of 4NP may be impacting the reproductive health of corals and threatening the persistence of coral reefs.

Keywords: UDP-glycosyltransferase, steroids, coral, endocrine disruption, 4-nonylphenol, coral reproduction

\section{INTRODUCTION}

Both marine and terrestrial ecosystems are in decline from anthropogenic sources of stress. Specifically, for corals, over $30 \%$ of the world's coral reefs have been lost in the last few decades, with an additional 30-40\% at risk of being lost by the year 2050 (National Academies of Sciences, Engineering, and Medicine, 2019). These losses are due to both abiotic and biotic factors, including rapid increases in the rate and magnitude of climate change, as well as increases in the concentration and distribution of environmental contaminants affecting water 
quality on a global scale. Within the broad range of environmental contaminants, endocrine disruptors (EDs) have received a great deal of interest. Broadly defined, EDs are compounds that interfere with the production, release, transport, metabolism, binding, action, or elimination of natural hormones responsible for homeostasis and developmental processes (Kavlock et al., 1996). While initial concerns of endocrine disruption were focused on humans, the ability EDs to impact wildlife, especially marine invertebrates, was quickly realized (Tyler et al., 1998; Ford and LeBlanc, 2020). Early studies focused on the ability of compounds to bind to steroid receptors as a surrogate for endocrine disrupting effects. However, later discoveries such as the activation of the retinoid $\mathrm{X}$ receptor being responsible for the imposex observed in dog whelk (Nucella lapillus) exposed to tributylin, have demonstrated the complexity of mechanisms that can result in homeostatic disruption (Blaber, 1970; Castro et al., 2007).

The weak xenoestrogen, 4-nonylphenol (4NP) has garnered interest due to its wide use in consumer, pharmaceutical, and industrial products as a surfactant to increase miscibility of chemicals in compound mixtures (Ying et al., 2002). Although $4 \mathrm{NP}$ is present in consumer products in the ethoxylate form, the parent molecule re-emerges in the environment as a breakdown product (Ahel et al., 1994). The presence of 4NP has been measured globally in sewage treatment effluents, freshwater and marine ecosystems, and sediments (Soares et al., 2008). 4NP can persist in aquatic habitats, with an estimated half-life of 58 days (Ekelund et al., 1993), readily bind to organic matter (John et al., 2000; Langford and Lester, 2002), and remain in sediments with an estimated half-life greater than 60 years (Shang et al., 1999).

The toxicity of $4 \mathrm{NP}$ has been extensively studied in aquatic algae, invertebrates, and fish (Servos, 1999; Staples et al., 2004). In aquatic organisms, the effect of $4 \mathrm{NP}$ is frequently associated with estrogen receptor agonism, resulting in endocrine disruption (White et al., 1994; Giesy et al., 2000). The effects of 4NP in marine species have been less studied than for freshwater organisms. In the phylum Cnidaria, only the acute (96 h) toxic threshold of 4NP in Hydra attenuata (a freshwater invertebrate) has been investigated (Pachura et al., 2005; PachuraBouchet et al., 2006). While acute toxicities are important, there exists a disconnect between the high lethal concentrations determined in acute studies and the relatively low levels observed in the environment. In the marine aquatic environment, the range of $4 \mathrm{NP}$ concentrations range between 0.1 and $4 \mu \mathrm{g} / \mathrm{L}$ (ppb), with highest reported levels at $10 \mu \mathrm{g} / \mathrm{L}$ or greater in industrial areas (Bolz et al., 2001; Kawahata et al., 2004; Soares et al., 2008). Therefore, studies are needed to determine the effect of sublethal, chronic exposure to 4NP at environmentally relevant levels on key groups of organisms.

The current investigation was designed to evaluate the impact of chronic (6 weeks), low dose exposure to 4NP (1 ppb) on the reef building coral, $P$. damicornis over its monthly reproductive cycle. This coral was chosen as it produces brooded planula larvae on a monthly cycle throughout the year in Hawaii (Richmond and Jokiel, 1984). A comprehensive analysis of the impact of $4 \mathrm{NP}$ on the molecular endocrinology of $P$. damicornis is presented that includes an evaluation of $4 \mathrm{NP}$ effects on the levels of steroid hormones present in the coral tissue, the activities of steroidogenic enzymes, activities of steroid clearance/detoxification enzymes, and activities of steroid regeneration enzymes.

\section{MATERIALS AND METHODS}

\section{Chemicals}

The following chemicals were used in this study: 4-methyl umbelliferone sodium salt (4-MU), MP Biomedicals (Solon, $\mathrm{OH}$, United States); 4-methyl umbelliferyl-beta-D-glucuronide (4-MU-G), Acros Organics (Geel, Belgium); 3'-phosphoadenosine 5'-phosphosulfate (PAPS), Calbiochem (San Diego, CA, United States); $\mathrm{NAD}^{+}$and NADPH, Calbiochem (San Diego, CA, United States); potassium hydroxide $(\mathrm{KOH})$, Fisher Chemicals (Fair Lawn, NJ, United States); and pregnenolone, TCI America (Portland, OR, United States). All other chemicals were purchased from Sigma Aldrich Company (St Louis, MO, United States) and were analytical grade or higher.

\section{Coral Collection and Experimental Procedures}

Whole coral colonies $(~ 15 \mathrm{~cm}$ diameter; $n=6)$ of $P$. damicornis were collected from Coconut Island in Kaneohe Bay, Oahu under Special Activities Permit 2009-42, granted by the Hawaii Department of Land and Natural Resources, Division of Aquatic Resources. Corals were selected at random, cleaned of any foreign organisms and placed in a quarantine tank for 14 days prior to introduction into flowing seawater tanks at the Kewalo Marine Laboratory (KML). The quarantine tank consisted of an open flow through system sea water table. All water leaving the isolation tank was filtered and sterilized using a SMART Ultraviolet Sterilizer Model 02025 (Emperor Aquatics Inc., Pottstown, PA, United States) prior to release. After isolation, colonies were maintained in separate seawater tanks and allowed to recuperate for at least 28 days from collection-associated stress and allowed to acclimatize to the KML seawater system [salinity of $36 \pm 1$ parts per thousand (ppt), temperature $27 \pm 2^{\circ} \mathrm{C}$ ] prior to exposure. The Kewalo seawater system consisted of an unfiltered open flow through system where seawater was furnished through a pipe with an intake $300 \mathrm{~m}$ offshore in $10 \mathrm{~m}$ deep water.

\section{4-Nonylphenol Solutions}

Seawater used in the experiments was collected from the KML water system and filtered using $0.2 \mu \mathrm{m}$ nitrocellulose membranes. A stock solution of $4 \mathrm{NP}$ was prepared in acetone at $0.1 \mathrm{mg} /$ $\mathrm{ml}$ or 100 parts per million (ppm). Working solutions at the final concentration of $1 \mathrm{ng} / \mathrm{ml}$ or 1 part per billion (ppb) were prepared by the addition of $10 \mu$ l of the acetone stock to $1 \mathrm{~L}$ of filtered seawater. Final solutions were made fresh before each water change. Acetone was used a carrier solvent to dissolve $4 \mathrm{NP}$ into solution. The carrier solvent control stock solutions were prepared in the same manner as the $4 \mathrm{NP}$ solutions; with the exception that acetone alone was added. 


\section{Coral Exposure to 4-Nonylphenol}

Coral colonies were assigned into either the carrier solvent control (acetone) group ( $n=3$ whole coral colonies) or the $1 \mathrm{ppb} 4 \mathrm{NP}$ group ( $n=3$ whole coral colonies). Dosing chambers for the exposure consisted of $2 \mathrm{~L}$ glass bowls, aerated using glass Pasteur pipettes and covered with Parafilm ${ }^{\circledR}$ to prevent evaporation. Dosing chambers were placed in water tables with running seawater to maintain temperature stability and were covered with a $50 \%$ shade cloth to decrease peak light levels. Temperature within the dosing chambers ranged from 25.5 to $28.5^{\circ} \mathrm{C}$. Water changes were performed every $24-48 \mathrm{~h}$.

Coral colonies were exposed to $4 \mathrm{NP}$ for a total of 6 weeks (42 days). No samples were taken for the first 2 weeks of exposure. After the initial 2 weeks, the corals were sampled on the lunar quarters (between 6 and 8 days), starting with the reproductive planulation event (0 time point), and ending the week before the following planulation event ( -1 time point). Coral branches $(\sim 7 \mathrm{~cm}$ tall and $2.5 \mathrm{~cm}$ wide) were removed from the colony at the base of the coral where the skeleton was devoid of tissue to avoid further stress to the colony. Samples were placed in conical $50 \mathrm{ml}$ polypropylene Falcon tubes, flash frozen with liquid nitrogen, and immediately placed in a $-80^{\circ} \mathrm{C}$ freezer until further processing.

\section{Preparation of Whole Cell Lysates and S9 Subcellular Fractions From Coral}

Corals tissue was removed from the skeleton using a Water Pik system and $0.2 \mu \mathrm{m}$ filtered seawater (FSW; Johannes and Wiebe, 1970). The resulting coral blastate was transferred to conical $50 \mathrm{ml}$ polypropylene Falcon tubes and spun at 10,000 $\mathrm{g}$ for $10 \mathrm{~min}$ at $4^{\circ} \mathrm{C}$ in a Sorvall RC-5B centrifuge (DuPont Instruments, San Pedro, CA, United States) to pelletize tissue and free-floating cells. The resulting pellets were resuspended and combined in $5 \mathrm{ml}$ of cold homogenization buffer [FSW; $1 \mathrm{mM}$ phenylmethylsulfonylfluoride (PMSF)] and homogenized on ice with an Ultra-Turrax homogenizer for $60 \mathrm{~s}$. The homogenate was placed in a $15 \mathrm{ml}$ Falcon tube and centrifuged at 2,000 $\mathrm{g}$ for $5 \mathrm{~min}$ at $4^{\circ} \mathrm{C}$ in an Eppendorf Centrifuge 5810R (Eppendorf, Hauppauge, NY, United States). The zooxanthellae pellet was discarded, and the supernatant was transferred to a new $15 \mathrm{ml}$ Falcon tube and spun again at 2,000 $\mathrm{g}$ for $3 \mathrm{~min}$ to remove any remaining zooxanthellae. The final supernatant, representing whole cell lysate (WCL), containing only coral tissue, was aliquoted and frozen at $-80^{\circ} \mathrm{C}$ until use. The S9 post-mitochondrial fraction of protein was obtained by processing the WCL using a glass homogenizer for 2 min (ca. 30 strokes). The resulting homogenate was centrifuged at $10,000 \mathrm{~g}$ for $10 \mathrm{~min}$ at $4^{\circ} \mathrm{C}$ in an Eppendorf 5415D Microcentrifuge (Eppendorf, Hauppauge, NY, United States). After this final centrifugation, the supernatant represents the S9 tissue fraction of coral. Protein concentrations of all samples were measured using the BCA method described by Smith et al. (1985) using bovine serum albumin as the protein standard.

\section{Quantifying Steroid Hormones}

Measurements of cholesterol and steroidal hormones were performed on the coral tissue WCL. All WCLs were normalized to $0.25 \mathrm{mg} / \mathrm{ml}$ for total and free cholesterol and $2 \mathrm{mg} / \mathrm{ml}$ for steroid hormone ELISA assays. Total and free cholesterol were measured by biochemical assay as per the manufacturer's instructions (Cayman Chemical, Ann Arbor, MI, United States). The steroid hormones estrone, $17 \beta$-estradiol, testosterone, and progesterone were measured by ELISA (ALPCO Immunoassays, Salem, NH, United States; Calbiotech, Spring Valley, CA, United States for progesterone), per the manufacturer's instructions. The specificity of antibodies raised to chemical structures is high, with cross reactivity to structurally related compounds being less than $6 \%$ for cholesterol, estrone, $17 \beta$-estradiol, testosterone, and progesterone, respectively.

\section{Enzyme Assays}

All steroidogenic assays were performed in $5 \mathrm{ml}$ glass tubes, unless specified, and subsequently aliquoted in triplicate into 96-well clear microplates. For clearance and regeneration enzyme assays, coral protein, assay buffer, and substrate were loaded into wells on microplates that were kept on ice. Microplates were pre-warmed inside a microplate reader (Spectra Max or Gemini XS, Molecular Devices, Sunnyvale, CA, United States) at $37^{\circ} \mathrm{C}$ for $5 \mathrm{~min}$ prior to the addition of the co-factors used to initiate the reaction. Fluorescence assays were performed in black, flat-bottomed plates, colorimetric assays in clear plates, and UV assays in optically clear microplates. For substrates dissolved in solvents, solvent was never more than $2 \%$ of the reaction volume; hence, solvent carrier properties should not have affected enzyme activities (Williams et al., 2008). Microplates were read using either a Spectra Max 340 Plus or Gemini XS (Molecular Devices, Sunnyvale, CA, United States). Individual enzyme activities were assessed as follows:

\section{3- $\beta$-Hydroxysteroid Dehydrogenase}

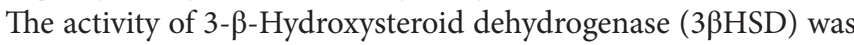
determined by measuring the conversion of pregnenolone to progesterone. Glass tubes were kept on ice while coral WCLs $(0.2 \mathrm{mg} / \mathrm{ml}$ final concentration) in $0.1 \mathrm{M}$ Tris- $\mathrm{HCl}$ buffer $\mathrm{pH}$ 7.4 containing $50 \mathrm{mM} \mathrm{MgCl}$ and $150 \mathrm{ng} / \mathrm{ml}$ pregnenolone were added. Tubes were pre-incubated for $30 \mathrm{~s}$ at $37^{\circ} \mathrm{C}$ in a hot water bath. Reactions were initiated through the addition of $1 \mathrm{mM} \mathrm{NAD}^{+}$and incubated at $37^{\circ} \mathrm{C}$ for $20 \mathrm{~min}$. After incubation, the reaction was terminated by plunging tubes into ice for $5 \mathrm{~min}$. Detection of progesterone was determined through ELISA and converted to $\mathrm{ng} / \mathrm{min} / \mathrm{mg}$ of protein using a standard curve of progesterone (manufacturer supplied).

\section{Cytochrome P450 17/17 $\alpha$-Hydroxylase}

Activity of CYP17 was determined using a method adapted from Holtroff and Koch (1940). Briefly, coral protein $(0.2 \mathrm{mg} / \mathrm{ml}$ final concentration) in $0.1 \mathrm{M}$ Tris- $\mathrm{HCl}$ buffer $\mathrm{pH} 7.4$ containing $50 \mathrm{mM} \mathrm{MgCl} 2$ and $500 \mu \mathrm{M} 17 \alpha$-hydroxypregnenolone were added to glass tubes on ice. Tubes were pre-incubated for $30 \mathrm{~s}$ at $37^{\circ} \mathrm{C}$ prior to reaction initiation through the addition of $1 \mathrm{mM}$ NADPH. Tubes were then incubated at $37^{\circ} \mathrm{C}$ for $5 \mathrm{~min}$. Reactions were terminated through the addition of an equal volume of $5 \mathrm{M} \mathrm{KOH}$. An equal volume of $2 \%$ 
m-dinitrobenze, in 95\% ethanol, was added and the color allowed to develop for $2 \mathrm{~min}$. The mixture was transferred to $1.5 \mathrm{ml}$ microcentrifuge tubes and spun at $10,000 \mathrm{~g}$ for $3 \mathrm{~min}$ in an Eppendorf Minispin centrifuge (Hauppauge, NY, United States) to pelletize the precipitate. Absorbance was determined at $\lambda=520 \mathrm{~nm}$ in triplicate wells and results transformed to nmoles/min/mg of protein using a standard curve generate through dilution of pure DHEA (0-1 mM).

\section{Cytochrome P450 19/Aromatase}

The activity of CYP19 was determined by measuring the conversion of testosterone to $17 \beta$-estradiol. Briefly, glass tubes were kept on ice while coral WCLs $(0.2 \mathrm{mg} / \mathrm{ml}$ final concentration) in $0.1 \mathrm{M}$ Tris- $\mathrm{HCl}$ buffer $\mathrm{pH} 7.4$, containing $50 \mathrm{mM} \mathrm{MgCl}_{2}$, and $10 \mathrm{ng} / \mathrm{ml}$ of testosterone were added. Tubes were pre-incubated at $37^{\circ} \mathrm{C}$ in a hot water bath. Reactions were initiated through the addition of $1 \mathrm{mM}$ NADPH and the tubes incubated at $37^{\circ} \mathrm{C}$ for $30 \mathrm{~min}$. After incubation, the reaction was terminated by placing the tubes into ice for $5 \mathrm{~min}$. Detection of estradiol was determined through ELISA and data were converted to $\mathrm{fg} / \mathrm{min} / \mathrm{mg}$ of protein using a standard curve of progesterone (manufacturer supplied).

\section{Glutathione-S-Transferase}

Activity of glutathione-S-transferase (GST) was determined using a method adapted from Habig et al. (1974) and González et al. (1989). Optically clear microplates (Greiner Bio-One, Monroe, NC, United States) were placed on ice and loaded with $0.5 \mathrm{mM}$ 1-chloro-2,4-dinitrobenzene (in DMSO) and coral protein $(0.1 \mathrm{mg} / \mathrm{ml})$. After pre-incubation $\left(3 \mathrm{~min}\right.$ at $\left.37^{\circ} \mathrm{C}\right)$, reactions were initiated through the addition of $1 \mathrm{mM}$ L-glutathione. Absorbance was monitored continuously at $\lambda=340 \mathrm{~nm}$. Total activity was calculated using Beer's Law with $\varepsilon=9.6 \mathrm{mM}^{-1} \mathrm{~cm}^{-1}$ (Habig et al., 1974).

\section{UDP-Glycosyltransferase}

Total UDP-glycosyltransferase (UGT) activity in coral protein $(0.3 \mathrm{mg} / \mathrm{ml})$ was determined using the method of Collier et al. (2000) with substrate 4-methylumbelliferone (4MU). The method was modified so that $50 \mu \mathrm{g} / \mathrm{ml}$ alamethicin (in DMSO) was used as the UGT activator and $5 \mathrm{mM}$ sacchrolactone was included in each reaction to inhibit $\beta$-glucuronidase activity. Fluorescence was monitored continuously at $355 \mathrm{~nm} \mathrm{ex} / 460 \mathrm{~nm}$ $\mathrm{em}$ and results were transformed to $\mathrm{pmol} / \mathrm{min} / \mathrm{mg}$ protein using a standard curve generated with $4-\mathrm{MU}$.

\section{$\beta$-Glucuronidase}

$\beta$-Glucuronidase activity was determined using the method of Trubetskoy and Shaw (1999). Microplates on ice were loaded with coral protein $(0.1 \mathrm{mg} / \mathrm{ml}$ final concentration) and buffer; plates were pre-incubated at $37^{\circ} \mathrm{C}$ for $5 \mathrm{~min}$ and the reaction initiated with $100 \mu \mathrm{M}$ 4MU-Glucuronide. Fluorescence was continuously monitored at $355 \mathrm{~nm}$ ex/460 nm em. Results were transformed to $\mathrm{pmol} / \mathrm{min} / \mathrm{mg}$ protein using a standard curve generated with 4-MU.

\section{Sulfotransferase 1A1}

The activity of sulfotransferase 1A1 (SULT1A1) was measured using the method of Frame et al. (2000). Coral protein (1 mg/ $\mathrm{ml}$ final concentration), $5 \mathrm{mM}$ para-nitrophenyl sulfate, and $0.1 \mathrm{mM}$ 2-naphthol were added to each well of a microtiter plate, pre-incubated for $5 \mathrm{~min}$ at $37^{\circ} \mathrm{C}$, and then the enzyme reaction was initiated by the addition of $60 \mu \mathrm{M}$ 3'-phosphoadenosine 5'-phosphosulfate (PAPS). Reactions proceeded for $1 \mathrm{~h}$, and then absorbance was measured at $\lambda=405 \mathrm{~nm}$. Total SULT1A1 activity was calculated using Beer's Law with $\varepsilon=18.2 \mathrm{mM}^{-1} \mathrm{~cm}^{-1}$ (Frame et al., 2000).

\section{Steroid Sulfatase}

Activity of the arylsulfatase isoform C, referred to as steroid sulfatase (STS), was determined using a modification of the method of Roy (1958). Microplates were kept on ice and coral protein in $0.1 \mathrm{M}$ Tris- $\mathrm{HCl}$ buffer $\mathrm{pH} 7.4$ containing $(0.5 \mathrm{mg} / \mathrm{ml}$ final concentration) was added to each well. The samples were pre-incubated for $5 \mathrm{~min}$ at $37^{\circ} \mathrm{C}$, and then reactions were initiated with the addition of $100 \mu \mathrm{M}$ para-nitrophenyl sulfate. Absorbance was monitored continuously at $\lambda=400 \mathrm{~nm}$ and results were generated using a standard curve of para-nitrophenol.

\section{Statistical Analyses}

Statistical analyses were performed using Prism 8.0 with statistical significance set at $\alpha=0.05$. (GraphPad Prism, San Diego CA, United States). Parametric statistics were performed, since all data approximated Gaussian distributions, and two-tailed student $t$-tests were used to assess differences between groups, with an $F$-test to compare variances. When paired sample $t$-tests were performed, the correlation coefficient was generated to assess the effectiveness of the pairing.

\section{RESULTS}

\section{Steroid Hormones}

No significant differences were detected between controls (CTL) and $4 \mathrm{NP}$ exposed corals at any time point in the lunar cycle for total or free cholesterol (Figures 1A,B). The same trend was observed for all steroid hormones (Figures 1C-F). A trend of increased testosterone in the $4 \mathrm{NP}$ exposed corals at the 0 and -1 time points, respectively, $(p=0.0839$ and 0.0608 , respectively, $t$-test), was observed, although these did not reach statistical significance (Figure 1F).

\section{Steroidogenic Enzymes}

Activity of $3 \beta \mathrm{HSD}$ was not altered by $4 \mathrm{NP}$ (Figure 2A). However, some significant effects on the activity of CYP17 and CYP19 were caused by 4NP exposure. The activity of CYP17 was significantly lowered by exposure to $4 \mathrm{NP}$ $(p=0.027)$ at the 0 time point (Figure 2B), while CYP19 activity was significantly higher as a result of $4 \mathrm{NP}$ exposure $(p=0.025)$ at the 1 time point (Figure 2C). Additionally, CYP19 activity of the $4 \mathrm{NP}$ exposed corals remained consistent 
A

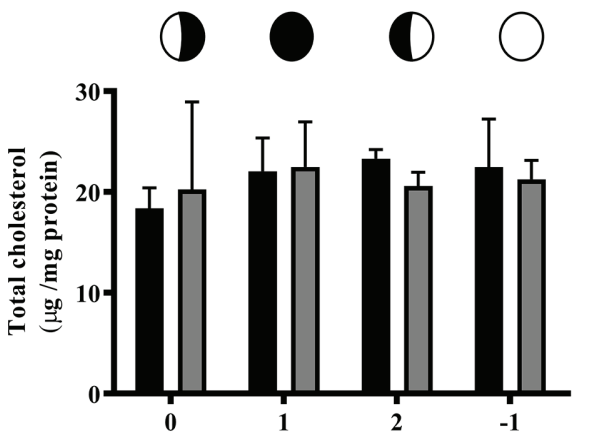

C

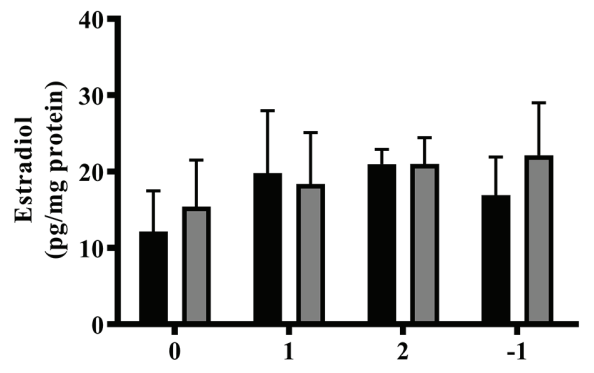

E

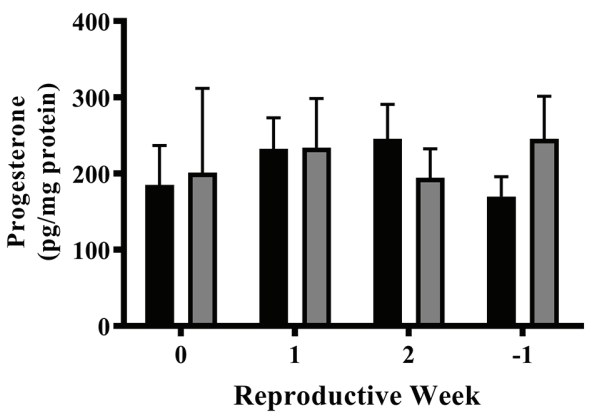

B
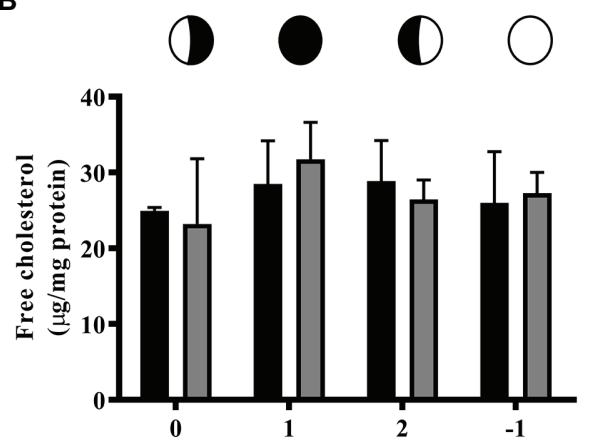

D

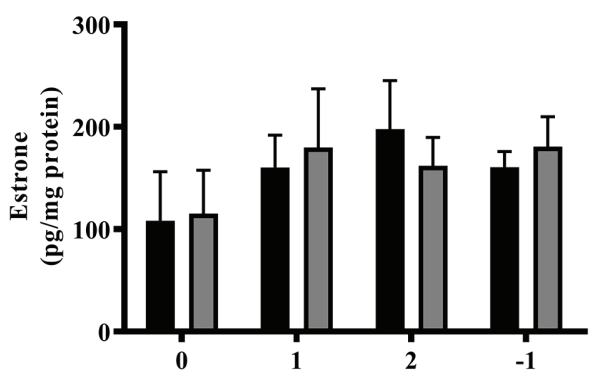

$\mathbf{F}$

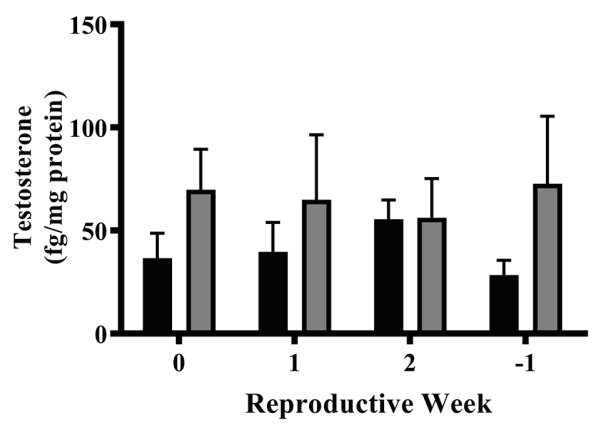

FIGURE 1 | Levels of cholesterol and steroid hormones over the lunar reproductive cycle in control corals and corals exposed to 4NP. (A) Total cholesterol, (B) free cholesterol, (C) $17 \beta$-estradiol, (D) estrone, (E) progesterone, and (F) testosterone. Circles with different fills represent the lunar cycle period in the order of 3rd quarter moon (planulation, time point 0), new moon (1 week after planulation, time point 1), 1st quarter moon (2 weeks after planulation, time point 2), and full moon (1 week before planulation, time point -1). Solid black bars represent control corals and gray bars represent corals chronically expose to $4 \mathrm{NP}$. Bars represent mean \pm SD for $n=3$ experiments, each assayed in triplicate.

over the lunar cycle with none of the levels at the different time points being significantly different from one another (Figure 2C). This is in contrast to the control corals whose CYP19 activity was significantly lower at the 1 and -1 time points compared to the other time points in the lunar cycle (Figure 2C).

\section{Steroid Conjugation/Deconjugation Enzymes}

Activity of the conjugation enzyme GST did not fluctuate over the lunar cycle and was unaffected by exposure to 4NP (Figure 3A). In contrast, the activity of UGT enzymes for the
CTL corals fluctuated over the lunar cycle, as previously reported (Rougée et al., 2014, 2015), with significantly higher UGT activity at the 2 time point compared to the 0 and -1 time points (One-way ANOVA $p=0.026$; Tukey's Multiple Comparison Test, Figure 3B). However, UGT activity in 4NP exposed corals did not fluctuate over the lunar cycle and was significantly higher compared to that of CTL corals at the 0 and -1 time points ( $p=0.027$ and 0.009 , respectively; two tailed unpaired $t$-test). The regeneration enzyme, $\beta$-glucuronidase, activities did not fluctuate over the lunar cycle and were not altered in the presence of $4 \mathrm{NP}$ (Figure $3 \mathrm{C}$ ). The increase in UGT activity on the 0 and -1 time points as a result of $4 \mathrm{NP}$ exposure, 
A

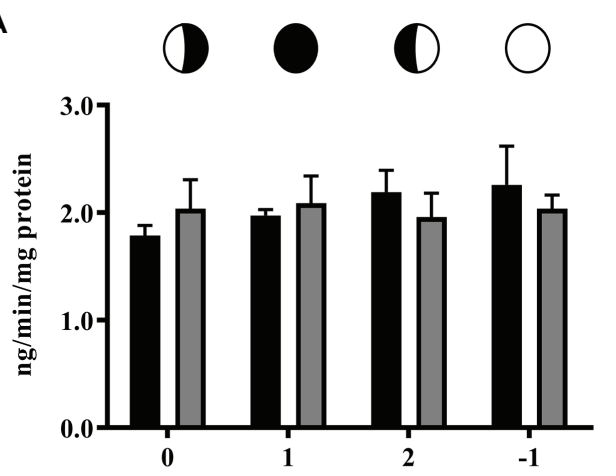

\section{B}

0000

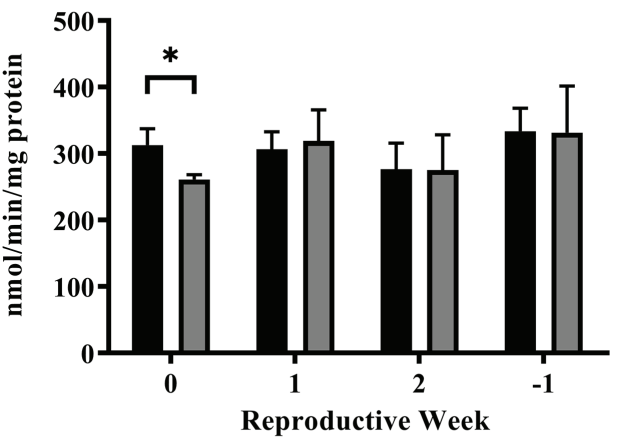

C

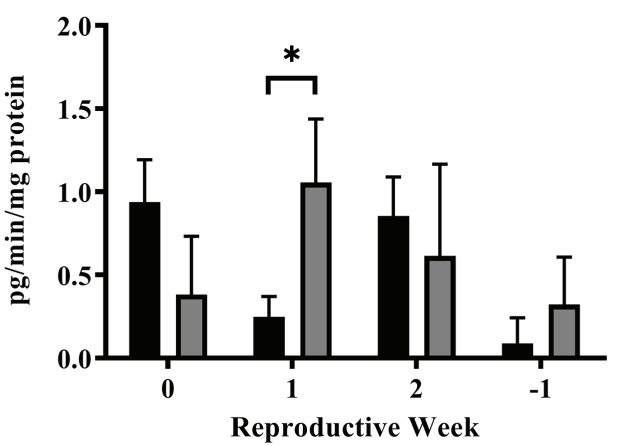

FIGURE 2 | Activity of steroidogenic enzymes over the lunar reproductive cycle in control corals and corals exposed to 4NP. (A) 3BHSD, (B) CYP17, and (C) CYP19. Circles with different fills represent the lunar cycle period in the order of 3rd quarter moon (planulation, time point 0), new moon (1 week after planulation, time point 1), 1st quarter moon (2 weeks after planulation, time point 2), and full moon (1 week before planulation, time point -1 ). Solid black bars represent control corals and gray bars represent corals chronically expose to 4NP. " $p \leq 0.05$ (unpaired $t$-test). Bars represents mean \pm SD for $n=3$ experiments, each assayed in triplicate.

coupled with a lack of change in $\beta$-glucuronidase, resulted in an increase of UGT: $\beta$-glucuronidase activity ratio of 2 - and $\sim 4$-fold, respectively, for the 0 and -1 time points (Table 1). This shifted the balance toward elimination as opposed to retention at the given time points. The activity of the reverse clearance enzyme STS was reduced over the lunar reproductive cycle. This reached significance at the 0 and -1 time points ( $p=0.009$ and 0.047 , respectively; two tailed unpaired $t$-test; Figure 3D).

Finally, the activity of SULT1A1 was not detected. The carrier solvents acetone and methanol have been found to significantly reduce and inhibit the activity of sulfotransferases (Arand et al., 1987; Ma et al., 2003). Since acetone exposure occurred over a prolonged period (6 weeks), a $1 \%$ final concentration of methanol was used as a carrier solvent for PMSF in the homogenization buffer, and SULT1A1 activity could not be detected in either the control or exposed coral, it is suspected that SULT1A1 activity was significantly affected by the presence of these carrier solvents in the experimental design.

\section{Planulae Release}

Planula larvae released during the first 4 weeks of the exposure was low to non-detectable. Planulae production began to increase in the weeks approaching the next planulation event ( 2 weeks before and 1 week before the lunar reproductive peak). A greater number of planulae were released by the CTL colonies compared to the 4NP exposed corals; however, this did not reach statistical significance due to the high variability between colonies (Figure 4).

\section{DISCUSSION}

Our data indicate that chronic environmental exposure to sublethal concentrations of $4 \mathrm{NP}$ results in changes in biotransformation and detoxification enzymes in the coral P. damicornis, affecting steroid homeostasis and endo- and xeno-biotic detoxification. Significant dysregulation was observed in enzymes associated with the detoxification of $4 \mathrm{NP}$ itself (UGT) as well as in the regulation of steroid hormones (UGT and STS; Müller et al., 1998), which may affect coral reproductive fitness and constrain dynamic protein protective responses to additional stressors such as reduced water quality and associated toxicant exposure.

Previous studies using the coral $P$. damicornis observed significant variation in activity of the UGT enzyme over its 
A

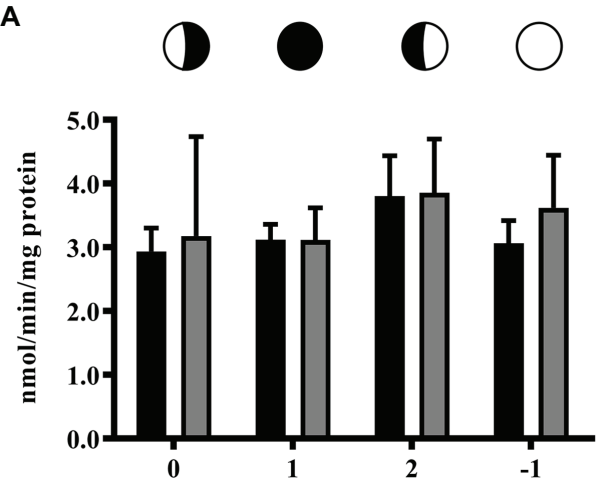

C

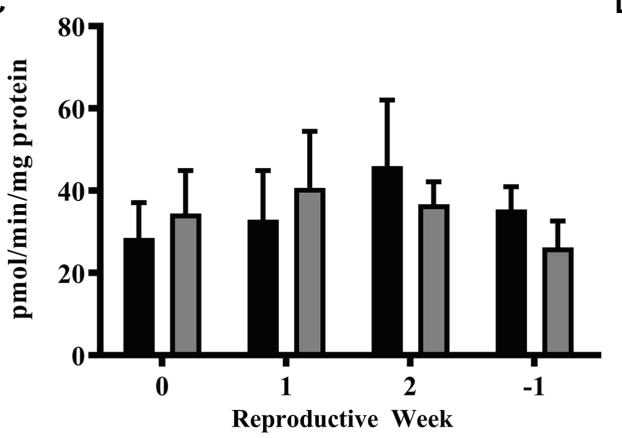

B

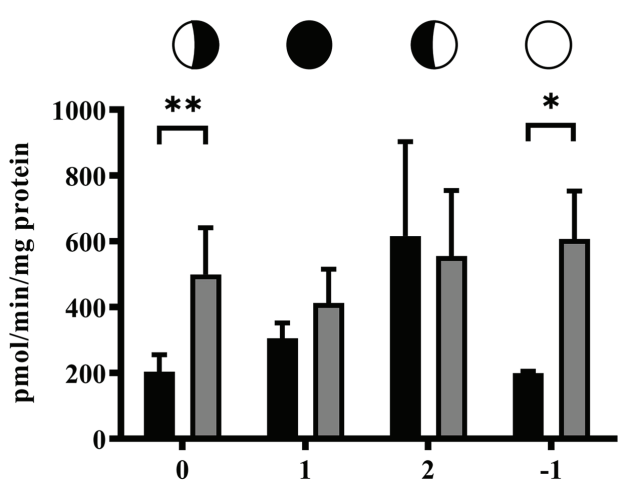

D

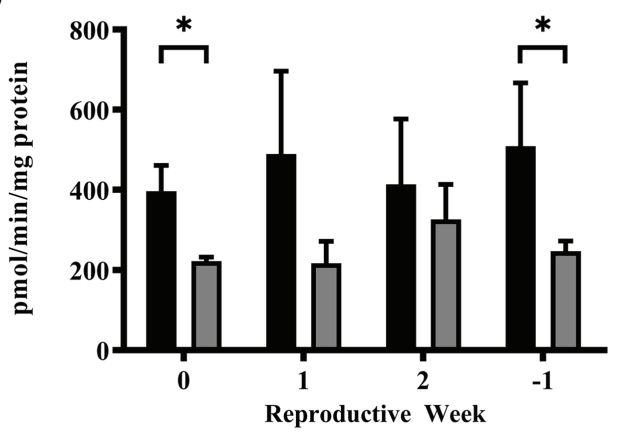

FIGURE 3 | Activity of steroid clearance/detoxification and regeneration enzymes over the lunar reproductive cycle in control corals and corals exposed to 4NP. (A) GST, (B) UGT, (C) $\beta$-glucuronidase, and (D) STS. Circles with different fills represent the lunar cycle period in the order of 3rd quarter moon (planulation, time point 0), new moon (1 week after planulation, time point 1), 1st quarter moon (2 weeks after planulation, time point 2), and full moon (1 week before planulation, time point -1). Solid black bars represent control corals and gray bars represent corals chronically expose to 4NP. Bars are mean \pm SD for $n=3$ experiments, each assayed in triplicate. $" p \leq 0.05$ and ${ }^{* *} p \leq 0.01$ (unpaired $t$-test).

TABLE 1 | Changes in the UGT: $\beta$-glucuronidase enzyme ratio over the coral lunar reproductive cycle time points.

\begin{tabular}{lrrrr}
\hline & \multicolumn{4}{c}{ Lunar time point } \\
\cline { 2 - 5 } Condition & \multicolumn{1}{c}{$\mathbf{0}$} & $\mathbf{1}$ & $\mathbf{2}$ & $\mathbf{- 1}$ \\
\hline Control & $7: 1$ & $9: 1$ & $13: 1$ & $6: 1$ \\
4-nonylphenol exposed & $15: 1$ & $10: 1$ & $15: 1$ & $23: 1$ \\
Fold change & 2.1 & 1.1 & 1.2 & 3.8 \\
\hline
\end{tabular}

0, planulation (3rd quarter moon); 1, 1 week after planulation (new moon); 2, 2 week after planulation (1st quarter moon); -1, 1 week before planulation (full moon).

lunar reproductive cycle, with low activity the week before and the week of planulation, followed by increased activity peaking 2 weeks after/before the monthly planulation event. This suggests that UGT activity is associated with the formation of planulae (Rougée et al., 2014, 2015). In the current study, exposure to $4 \mathrm{NP}$ resulted in sustained increases in UGT activities, possibly associated with the dual role of UGT in detoxification. While many studies in invertebrates explore the activities of the CYP enzymes, less attention has been given to the role of conjugation enzymes in the detoxification of xenobiotics. Recent research has identified the presence of UGT enzymes in a variety of invertebrates, linking them to pesticide detoxification as well as providing a mechanism for pesticide resistance (Erban et al., 2017; Li et al., 2018; Pan et al., 2018; Zhou et al., 2019). In the case of 4NP, glucuronidation is a predominant pathway for elimination in a variety of organisms including rats, fish, and cockroaches (Knaak et al., 1966; Coldham et al., 1998; Daidoji et al., 2006). Therefore, it is likely that the observed increase in UGT in $P$. damicornis has a role in the metabolic elimination of $4 \mathrm{NP}$ from the system, in addition to other homeostatic roles such as steroid balance.

The effect of the change in UGT activity extends beyond detoxication and into pathways associated with reproduction. The activity of the reverse cleavage enzyme, $\beta$-glucuronidase, remained consistent over the lunar cycle and did not fluctuate in response to $4 \mathrm{NP}$ exposure. The ratio of these enzymes (UGT: $\beta$-glucuronidase) can provide insights into the balance of homeostasis by describing the predominant direction of metabolism: removal or regeneration of compounds. This ratio has previously been shown to shift over the reproductive cycle of $P$. damicornis with higher rates of clearance for endoand xeno-biotics 2 weeks before and 2 weeks after planulation, as compared to the intervening weeks where the balance of UGT: $\beta$-glucuronidase entailed a greater component of recycling (Rougée et al., 2014, 2015). The dynamic changes in the UGT: $\beta$-glucuronidase ratio over the reproductive cycle were 


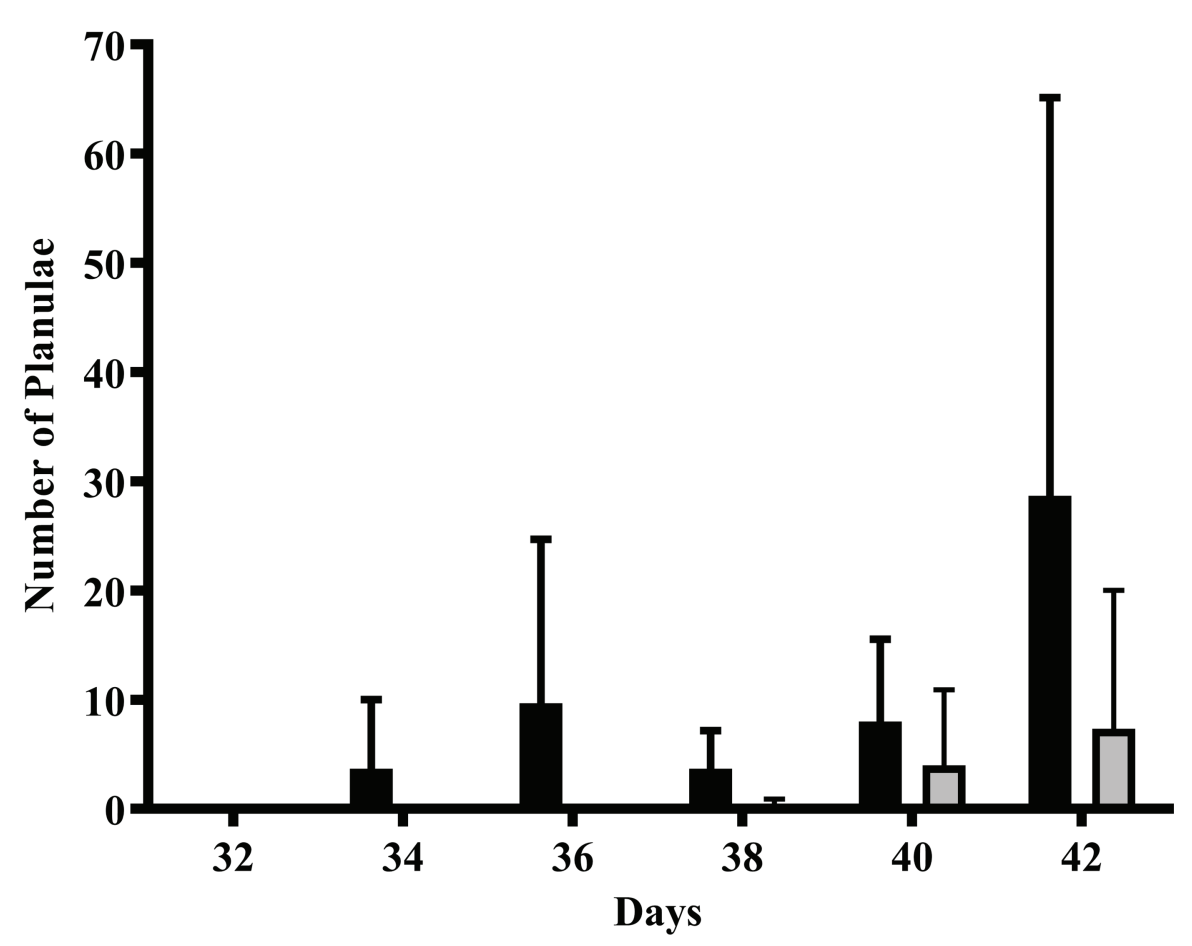

FIGURE 4 | The effect of 4NP exposure on the release of planulae leading up to the subsequent planulation event. Solid black bars represent control corals and gray bars represent corals chronically expose to 4NP. Error bars are mean \pm SD for $n=3$ separate experiments (in triplicate each time).

driven by changes in the UGT enzymes, not $\beta$-glucuronidase. In the current study, the increase in the ratio of UGT: $\beta$ glucuronidase throughout the reproductive lunar cycle for $P$. damicornis resulted in higher rates of clearance for compounds at points in the lunar cycle where conservation of chemicals is favored. Empirically, skewing the balance of chemical clearance/regeneration in this manner would cause excessive excretion of endogenous ligands (such as steroids) normally conserved for use in coral tissues during this time period. The release of steroid hormones from coral tissue into surrounding seawater has been observed as a cue for reproductive events in corals (Twan et al., 2006). Therefore, dysregulation in the timing and release of steroid hormones into the seawater could potentially result in altered reproductive events. Additionally, the constant presence of steroid hormones in the environment can decrease reproductive potential as was previously observed in the coral Montipora capitata when exposed to continuous estradiol levels for 3-weeks prior to a reproductive event (Tarrant et al., 2004).

One of the major metabolic routes of estradiol elimination is glucuronidation (Hum et al., 1999). Consequently, upon 4NP exposure, the estradiol tissue levels would be expected to decrease in response. However, our current study did not detect a decrease in estradiol. We ascribe this to an observed increase in CYP19 (aromatase) activity which is responsible for the conversion of C19 steroids (e.g., testosterone) into estradiol (Janer and Porte, 2007). Therefore, we propose a dynamic balance occurring where increases in CYP19 are in response to greater UGT activity as an adaptive response to environmental stimuli, to maintain endocrine homeostasis. While this was observed as a trend, the lack of statistical significance leads us to cautiously propose this mechanism. There is clear evidence that toxicants can impact alternate pathways affecting endocrine homeostasis. For example, it was recently demonstrated that chronic exposure of the bumblebee, Bombus terrestris, to the pesticide imidacloprid suppressed the mevalonate pathway, which is tightly connected to the synthesis of sterols (Goldstein and Brown, 1990; Erban et al., 2019). Affecting the synthesis of sterols is harmful for non-targets, and these effects can be chronic, affecting direct synthesis of steroid hormones and thus behavior and reproduction (Crisp et al., 1998; Kuervers et al., 2003; Clotfelter et al., 2004; Baglan et al., 2018).

In contrast to consistently elevated UGT activity during the reproductive cycle as a result of $4 \mathrm{NP}$ exposure, STS enzyme activity was consistently decreased. This affects another major conjugation pathway intimately associated with steroids, namely sulfation. Similar to the UGT: $\beta$-glucuronidase inter-relationship, regulation of steroid hormones and other endogenous compounds can be affected by the balance between SULT:STS clearance and regeneration partners (Mueller et al., 2015). As an example, the steroid hormone dehydroepiandrosterone (DHEA) is regulated by this pathway in most mammals (except rodents; van Weerden et al., 1992; Mueller et al., 2015). A circulating reservoir of the sulfonylated (at the oxygen atom) metabolite, dehydroepiandrosterone sulfate (DHEAS), is maintained until the need for DHEA arises (Mueller et al., 2015; 
Geyer et al., 2017; Gabai et al., 2020). When DHEA is required, STS enzymes cleave the sulfate to regenerate the parent compound. This is bio-energetically conservative for the organism as compared to de novo synthesis. Therefore, decreases in STS activity can impact this delicate balance, forcing the organism to compensate for decreased levels of recirculated enzyme through de novo production (Garbarino and Sturley, 2005; Tobler et al., 2007). Aside from mammalian physiology, it is known that STS is important for desulfonation of DHEAS in normal growth and development, as well as controlling the rate of deconjugation of estrone sulfate in many organisms, likely also of relevance to coral as well (Mueller et al., 2015). If the coral maintains a reservoir of a sulfonylated ligand (such as DHEAS or estrone-S) that requires cleavage by STS for regeneration into the active parent ligand (DHEA and estrone, respectively), inhibition of STS could alter the finelytuned balance of these chemicals. Furthermore, levels of the parent compound will decrease as sulfonylation continues and, in the case of corals reported here, glucuronidation is increased. This would force corals to compensate by producing more parent compound de novo, which is both energetically costly for the organism and may be disruptive at local tissue levels (Brown and Sharpe, 2016). The opportunity cost of de novo synthesis is likely to affect all processes in which these molecules take part, including behavior, development, and reproduction. This is consistent with our observation that the corals exposed to $4 \mathrm{NP}$ released few planula during the days around the reproductive planulation event as compared to the control corals. The duality of protein functions in organisms is not surprising, but is also concerning. Allocation to detoxification over reproduction is adaptive for immediate survival of individuals, but deleterious to long-term survival at the population level, ultimately with serious consequences for the persistence and survival of corals reefs.

In contrast to the other major Phase II enzymes, GST activities in corals did not change with exposure to 4NP. Previous findings in the mussel Mytilus galloprovincialis, showed a dose-dependent increase in GST activities upon chronic exposure (30 days) to $4 \mathrm{NP}$, suggesting upregulation of GST as a survival mechanism (Vidal-Liñán et al., 2015). Although we did not observe a change in GST in corals, this is likely a dose-response effect. GST activity was significantly increased at $50 \mu \mathrm{g} / \mathrm{L}(50 \mathrm{ppb})$ or greater in the mussel study cited above, which is exponentially higher than our current study (1 ppb). The observation by Vidal-Liñán et al. (2015) that the increased activity of GST in response to 4NP exposure continued to increase even after a 10-day depurination period is concerning as it suggests that $4 \mathrm{NP}$ accumulates in the tissues over chronic exposure. In addition to dose-response effects, inter-species and inter-strain differences within a species are expected. This is also illustrated by Riva et al. (2010), who observed no change in GST activity in the zebra mussel (Dreissena polymorpha) at 4NP concentrations up to and including $50 \mu \mathrm{g} / \mathrm{L}(\mathrm{ppb})$. Therefore, even without considering that coral is a very different invertebrate to bivalve mollusks, even with the species "mussel" at $50 \mu \mathrm{g} / \mathrm{L}, 4 \mathrm{NP}$ M. galloprovincialis has significantly deregulated GST, but
D. polymorpha did not (Riva et al., 2010; Vidal-Liñán et al., 2015). This highlights the care needed when comparing dynamic responses between organisms. Although we did not observe changes at the lower concentration of $4 \mathrm{NP}$, it is possible that given a longer exposure, significant accumulation of $4 \mathrm{NP}$ levels could be reached that would elicit an effect.

Future assessments of sublethal exposure to toxicants should balance the length of exposure and concentration in order to fully understand the chronic effects these compounds may have. This could help to determine causation for the initial significant decrease in CYP17 activity in 4NP exposure or the lack of activity changes in $3 \beta \mathrm{HSD}$ observed in this study, both upstream pathways to the formation of testosterone (Janer and Porte, 2007). Finally, it is important to stress that while many inferences of steroid biochemistry pathways are made from the extensive knowledge of human pathways, and despite the commonality of steroids in Animal Kingdom; their regulatory mechanisms almost certainly vary (Ford and LeBlanc, 2020).

The presence of an array of steroid production and elimination proteins in simple, evolutionarily primitive organisms such as corals is unsurprising, considering their success over millions of years, the fundamental role(s) of steroids in animals, and the multiplicity of overlapping roles for detoxication enzymes. In a world of increasing anthropogenic stressors, particularly widespread toxicants in the marine environment, the ability of diverse taxa of invertebrates to express protective proteins is essential to their survival. Indeed, xenobiotic metabolizing enzymes are under considerable evolutionary pressure and continue to evolve widely in many animal, insect, and plant species in response to increasing environmental exposure (Bock, 2016). The expression of conjugation enzymes, that play role(s) in homeostasis for nutrients, hormones, and signaling pathways, as well as detoxication is foundational to the survival of both individuals and ecosystems. Further investigation to identify other such enzymes, as well as fully characterize and understand the role of these proteins within corals and other invertebrates is critical for scientifically based interventions to understand the dynamic interplay between exposure and adaptation. Continued development of these types of tools, such as the ones presented herein, to help diagnose the effect of xenobiotic contaminants can improve efforts toward the protection and restoration of coral reefs that are of great ecological, economic, and cultural value world-wide.

\section{DATA AVAILABILITY STATEMENT}

The raw data supporting the conclusions of this article will be made available by the authors, without undue reservation.

\section{AUTHOR CONTRIBUTIONS}

LR, RR, and AC participated in research design, contributed to new reagents, or analytical tools, performed data analysis, and wrote or contributed to the writing of the manuscript. 
LR conducted experiments. All authors contributed to the article and approved the submitted version.

\section{FUNDING}

Partial support for this research was provided by the National Oceanic and Atmospheric Administration grant \# NA09NOS4780178, the National Science Foundation FSML Program award \# 1227183, and the National Fish and Wildlife Foundation grant \# 2008-0061-016. The views and conclusions contained in this document are those of the authors and should

\section{REFERENCES}

Ahel, M., Giger, W., and Koch, M. (1994). Behaviour of alkylphenol polyethoxylate surfactants in the aquatic environment-I. occurrence and transformation in sewage treatment. Water Res. 28, 1131-1142. doi: 10.1016/0043-1354(94) 90200-3

Arand, M., Robertson, L. W., and Oesch, F. (1987). A fluorometric assay for quantitating phenol sulfotransferase activities in homogenates of cells and tissues. Anal. Biochem. 163, 546-551. doi: 10.1016/0003-2697(87)90261-2

Baglan, H., Lazzari, C. R., and Guerrieri, F. J. (2018). Glyphosate impairs learning in Aedes aegypti mosquito larvae at field-realistic doses. J. Exp. Biol. 221:jeb187518. doi: 10.1242/jeb.187518

Blaber, S. J. M. (1970). The occurrence of a penis-like outgrowth behind the right tentacle in spent females of Nucella lapillus (L.). J. Molluscan Stud. 39, 231-233. doi: 10.1093/oxfordjournals.mollus.a065097

Bock, K. W. (2016). The UDP-glycosyltransferase (UGT) superfamily expressed in humans, insects and plants: animal-plant arms-race and co-evolution. Biochem. Pharmacol. 99, 11-17. doi: 10.1016/j.bcp.2015.10.001

Bolz, U., Hagenmaier, H., and Körner, W. (2001). Phenolic xenoestrogens in surface water, sediments, and sewage sludge from Baden-Württemberg, south-West Germany. Environ. Pollut. 115, 291-301. doi: 10.1016/ S0269-7491(01)00100-2

Brown, A. J., and Sharpe, L. J. (2016). "Chapter 11: Cholesterol synthesis" in Biochemistry of lipids, lipoproteins and membranes. 6th Edn. eds. N. D. Ridgway and R. S. McLeod (Boston: Elsevier), 327-358.

Castro, L. F. C., Lima, D., Machado, A., Melo, C., Hiromori, Y., Nishikawa, J., et al. (2007). Imposex induction is mediated through the retinoid $\mathrm{X}$ receptor signalling pathway in the neogastropod Nucella lapillus. Aquat. Toxicol. 85, 57-66. doi: 10.1016/j.aquatox.2007.07.016

Clotfelter, E. D., Bell, A. M., and Levering, K. R. (2004). The role of animal behaviour in the study of endocrine-disrupting chemicals. Anim. Behav. 68, 665-676. doi: 10.1016/j.anbehav.2004.05.004

Coldham, N. G., Sivapathasundaram, S., Dave, M., Ashfield, L. A., Pottinger, T. G., Goodall, C., et al. (1998). Biotransformation, tissue distribution, and persistence of 4-nonylphenol residues in juvenile rainbow trout (Oncorhynchus mykiss). Drug Metab. Dispos. 26, 347-354.

Collier, A. C., Tingle, M. D., Keelan, J. A., Paxton, J. W., and Mitchell, M. D. (2000). A highly sensitive fluorescent microplate method for the determination of UDP-glucuronosyl transferase activity in tissues and placental cell lines. Drug Metab. Dispos. 28, 1184-1186.

Crisp, T. M., Clegg, E. D., Cooper, R. L., Wood, W. P., Anderson, D. G., Baetcke, K. P., et al. (1998). Environmental endocrine disruption: an effects assessment and analysis. Environ. Health Perspect. 106(Suppl. 1), 11-56. doi: 10.1289/ehp.98106s111

Daidoji, T., Ozawa, M., Sakamoto, H., Sako, T., Inoue, H., Kurihara, R., et al. (2006). Slow elimination of nonylphenol from rat intestine. Drug Metab. Dispos. 34, 184-190. doi: 10.1124/dmd.105.007229

Ekelund, R., Granmo, A., Magnusson, K., Berggren, M., and Bergman, A. (1993). Biodegradation of 4-nonylphenol in seawater and sediment. Environ. Pollut. 79, 59-61. doi: 10.1016/0269-7491(93)90178-Q

Erban, T., Harant, K., Chalupnikova, J., Kocourek, F., and Stara, J. (2017). Beyond the survival and death of the deltamethrin-threatened pollen beetle not be interpreted as representing the opinions or policies of the U.S. Government or the National Fish and Wildlife Foundation and its funding sources. Mention of trade names or commercial products does not constitute their endorsement by the U.S. Government, or the National Fish and Wildlife Foundation or its funding sources

\section{ACKNOWLEDGMENTS}

The content of this manuscript has been published as part of the doctoral thesis of LR (Rougée, 2011).

Meligethes aeneus: an in-depth proteomic study employing a transcriptome database. J. Proteome 150, 281-289. doi: 10.1016/j.jprot.2016.09.016

Erban, T., Sopko, B., Talacko, P., Harant, K., Kadlikova, K., Halesova, T., et al. (2019). Chronic exposure of bumblebees to neonicotinoid imidacloprid suppresses the entire mevalonate pathway and fatty acid synthesis. J. Proteome 196, 69-80. doi: 10.1016/j.jprot.2018.12.022

Ford, A. T., and LeBlanc, G. A. (2020). Endocrine disruption in invertebrates: a survey of research progress. Environ. Sci. Technol. 54, 13365-13369. doi: 10.1021/acs.est.0c04226

Frame, L. T., Ozawa, S., Nowell, S. A., Chou, H. C., DeLongchamp, R. R., Doerge, D. R., et al. (2000). A simple colorimetric assay for phenotyping the major human thermostable phenol sulfotransferase (SULT1A1) using platelet cytosols. Drug Metab. Dispos. 28, 1063-1068.

Gabai, G., Mongillo, P., Giaretta, E., and Marinelli, L. (2020). Do dehydroepiandrosterone (DHEA) and its sulfate (DHEAS) play a role in the stress response in domestic animals? Front. Vet. Sci. 7:588835. doi: $10.3389 /$ fvets. 2020.588835

Garbarino, J., and Sturley, S. L. (2005). Homoeostatic systems for sterols and other lipids. Biochem. Soc. Trans. 33, 1182-1185. doi: 10.1042/BST0331182

Geyer, J., Bakhaus, K., Bernhardt, R., Blaschka, C., Dezhkam, Y., Fietz, D., et al. (2017). The role of sulfated steroid hormones in reproductive processes. J. Steroid Biochem. Mol. Biol. 172, 207-221. doi: 10.1016/j.jsbmb.2016.07.002

Giesy, J. P., Pierens, S. L., Snyder, E. M., Miles-Richardson, S., Kramer, V. J., Snyder, S. A., et al. (2000). Effects of 4-nonylphenol on fecundity and biomarkers of estrogenicity in fathead minnows (Pimephales promelas). Environ. Toxicol. Chem. 19, 1368-1377. doi: 10.1897/1551-5028(2000)019<1368:EONOFA >2.3.CO;2

Goldstein, J. L., and Brown, M. S. (1990). Regulation of the mevalonate pathway. Nature 343, 425-430. doi: 10.1038/343425a0

González, P., Tuñón, M. J., Manrique, V., Garcia-Pardo, L. A., and González, J. (1989). Changes in hepatic cytosolic glutathione S-transferase enzymes induced by clotrimazole treatment in rats. Clin. Exp. Pharmacol. Physiol. 16, 867-871. doi: 10.1111/j.1440-1681.1989.tb01526.x

Habig, W. H., Pabst, M. J., and Jakoby, W. B. (1974). Glutathione S-transferases. The first enzymatic step in mercapturic acid formation. J. Biol. Chem. 249, 7130-7139. doi: 10.1016/S0021-9258(19)42083-8

Holtroff, A. F., and Koch, F. C. (1940). The colorimetric estimation of 17-ketosteroids and their application to urine extracts. J. Biol. Chem. 135, 377-392. doi: 10.1016/S0021-9258(18)73105-0

Hum, D. W., Bélanger, A., Lévesque, É., Barbier, O., Beaulieu, M., Albert, C., et al. (1999). Characterization of UDP-glucuronosyltransferases active on steroid hormones. J. Steroid Biochem. Mol. Biol. 69, 413-423. doi: 10.1016/ S0960-0760(99)00061-8

Janer, G., and Porte, C. (2007). Sex steroids and potential mechanisms of non-genomic endocrine disruption in invertebrates. Ecotoxicology 16, 145-160. doi: 10.1007/s10646-006-0110-4

Johannes, R. E., and Wiebe, W. J. (1970). Method for determination of coral tissue biomass and composition. Limnol. Oceanogr. 15, 822-824. doi: 10.4319/ lo.1970.15.5.0822

John, D. M., House, W. A., and White, G. F. (2000). Environmental fate of nonylphenol ethoxylates: differential adsorption of homologs to components of river sediment. Environ. Toxicol. Chem. 19, 293-300. doi: 10.1002/ etc.5620190207 
Kavlock, R. J., Daston, G. P., DeRosa, C., Fenner-Crisp, P., Gray, L. E., Kaattari, S., et al. (1996). Research needs for the risk assessment of health and environmental effects of endocrine disruptors: a report of the U.S. EPA-sponsored workshop. Environ. Health Perspect. 104(Suppl. 4), 715-740. doi: 10.1289/ehp.96104s4715

Kawahata, H., Ohta, H., Inoue, M., and Suzuki, A. (2004). Endocrine disrupter nonylphenol and bisphenol a contamination in Okinawa and Ishigaki Islands, Japan--within coral reefs and adjacent river mouths. Chemosphere 55, 1519-1527. doi: 10.1016/j.chemosphere.2004.01.032

Knaak, J. B., Eldridge, J. M., and Sullivan, L. J. (1966). Excretion of certain polyethylene glycol ether adducts of nonylphenol by the rat. Toxicol. Appl. Pharmacol. 9, 331-340. doi: 10.1016/0041-008X(66)90129-3

Kuervers, L. M., Jones, C. L., O’Neil, N. J., and Baillie, D. L. (2003). The sterol modifying enzyme LET-767 is essential for growth, reproduction and development in Caenorhabditis elegans. Mol. Gen. Genomics. 270, 121-131. doi: 10.1007/s00438-003-0900-9

Langford, K., and Lester, J. N. (2002). "Fate and behavior of endocrine disrupters in wastewater treatment processes" in Endocrine disrupters in wastewater and sludge treatment processes. eds. J. W. Birkett and J. N. Lester (Boca Raton, FL: IWA Publishing), 99-159.

Li, X., Shi, H., Gao, X., and Liang, P. (2018). Characterization of UDPglucuronosyltransferase genes and their possible roles in multi-insecticide resistance in Plutella xylostella (L.). Pest Manag. Sci. 74, 695-704. doi: 10.1002/ ps. 4765

Ma, B., Shou, M., and Schrag, M. L. (2003). Solvent effect on cDNA-expressed human sulfotransferase (SULT) activities in vitro. Drug Metab. Dispos. 31, 1300-1305. doi: 10.1124/dmd.31.11.1300

Mueller, J. W., Gilligan, L. C., Idkowiak, J., Arlt, W., and Foster, P. A. (2015). The regulation of steroid action by sulfation and desulfation. Endocr. Rev. 36, 526-563. doi: 10.1210/er.2015-1036

Müller, S., Schmid, P., and Schlatter, C. (1998). Pharmacokinetic behavior of 4-nonylphenol in humans. Environ. Toxicol. Pharmacol. 5, 257-265. doi: 10.1016/S1382-6689(98)00009-X

National Academies of Sciences, Engineering, and Medicine (2019). A research review of interventions to increase the persistence and resilience of coral reefs. Washington, DC: The National Academies Press.

Pachura, S., Cambon, J. P., Blaise, C., and Vasseur, P. (2005). 4-nonylphenolinduced toxicity and apoptosis in Hydra attenuata. Environ. Toxicol. Chem. 24, 3085-3091. doi: 10.1897/04-669R.1

Pachura-Bouchet, S., Blaise, C., and Vasseur, P. (2006). Toxicity of nonylphenol on the cnidarian Hydra attenuata and environmental risk assessment. Environ. Toxicol. 21, 388-394. doi: 10.1002/tox.20201

Pan, Y., Tian, F., Wei, X., Wu, Y., Gao, X., Xi, J., et al. (2018). Thiamethoxam resistance in Aphis gossypii glover relies on multiple UDPglucuronosyltransferases. Front. Physiol. 9:322. doi: 10.3389/fphys.2018.00322

Richmond, R., and Jokiel, P. (1984). Lunar periodicity in larva release in the reef coral Pocillopora damicornis at Enewetak and Hawaii.

Riva, C., Porte, C., Binelli, A., and Provini, A. (2010). Evaluation of 4-nonylphenol in vivo exposure in Dreissena polymorpha: bioaccumulation, steroid levels and oxidative stress. Comp. Biochem. Physiol. C Toxicol. Pharmacol. 152, 175-181. doi: 10.1016/j.cbpc.2010.04.004

Rougée, L. R. A. (2011). Expression and activity of xenobiotic metabolizing enzymes in the reef coral Pocillopora damicornis. dissertation. Honolulu, (HI): University of Hawaii at Manoa.

Rougée, L. R. A., Richmond, R. H., and Collier, A. C. (2014). Natural variations in xenobiotic-metabolizing enzymes: developing tools for coral monitoring. Coral Reefs 33, 523-535. doi: 10.1007/s00338-014-1136-3

Rougée, L. R. A., Richmond, R. H., and Collier, A. C. (2015). Molecular reproductive characteristics of the reef coral Pocillopora damicornis. Comp. Biochem. Physiol. Part A Mol. Integr. Physiol. 189, 38-44. doi: 10.1016/j. cbpa.2015.07.012

Roy, A. B. (1958). Comparative studies on the liver sulphatases. Biochem. J. 68, 519-528. doi: 10.1042/bj0680519

Servos, M. R. (1999). Review of the aquatic toxicity, estrogenic responses and bioaccumulation of alkylphenols and alkylphenol polyethoxylates. Water Qual. Res. J. Canada 34, 123-178.
Shang, D. Y., Macdonald, R. W., and Ikonomou, M. G. (1999). Persistence of nonylphenol ethoxylate surfactants and their primary degradation products in sediments from near a municipal outfall in the strait of Georgia, British Columbia, Canada. Environ. Sci. Technol. 33, 1366-1372. doi: 10.1021/es980966z

Smith, P. K., Krohn, R. I., Hermanson, G. T., Mallia, A. K., Gartner, F. H., Provenzano, M. D., et al. (1985). Measurement of protein using bicinchoninic acid. Anal. Biochem. 150, 76-85. doi: 10.1016/0003-2697(85)90442-7

Soares, A., Guieysse, B., Jefferson, B., Cartmell, E., and Lester, J. N. (2008). Nonylphenol in the environment: a critical review on occurrence, fate, toxicity and treatment in wastewaters. Environ. Int. 34, 1033-1049. doi: 10.1016/j.envint.2008.01.004

Staples, C., Mihaich, E., Carbone, J., Woodburn, K., and Klecka, G. (2004). A weight of evidence analysis of the chronic ecotoxicity of nonylphenol ethoxylates, nonylphenol ether carboxylates, and nonylphenol. Hum. Ecol. Risk Assess. Int. J. 10, 999-1017. doi: 10.1080/10807030490887122

Tarrant, A. M., Atkinson, M. J., and Atkinson, S. (2004). Effects of steroidal estrogens on coral growth and reproduction. Mar. Ecol. Prog. Ser. 269, 121-129. doi: 10.3354/meps 269121

Tobler, M., Nilsson, J. -K., and Nilsson, J. F. (2007). Costly steroids: egg testosterone modulates nestling metabolic rate in the zebra finch. Biol. Lett. 3, 408-410. doi: 10.1098/rsbl.2007.0127

Trubetskoy, O. V., and Shaw, P. M. (1999). A fluorescent assay amenable to measuring production of beta-D-glucuronides produced from recombinant UDP-glycosyl transferase enzymes. Drug Metab. Dispos. 27, 555-557.

Twan, W. H., Hwang, J. S., Lee, Y. H., Wu, H. F., Tung, Y. H., and Chang, C. F. (2006). Hormones and reproduction in scleractinian corals. Comp. Biochem. Physiol. Part A Mol. Integr. Physiol. 144, 247-253. doi: 10.1016/j.cbpa.2006. 01.011

Tyler, C. R., Jobling, S., and Sumpter, J. P. (1998). Endocrine disruption in wildlife: a critical review of the evidence. Crit. Rev. Toxicol. 28, 319-361. doi: 10.1080/10408449891344236

van Weerden, W. M., Bierings, H. G., van Steenbrugge, G. J., de Jong, F. H., and Schröder, F. H. (1992). Adrenal glands of mouse and rat do not synthesize androgens. Life Sci. 50, 857-861. doi: 10.17219/acem/95039

Vidal-Liñán, L., Bellas, J., Salgueiro-González, N., Muniategui, S., and Beiras, R. (2015). Bioaccumulation of 4-nonylphenol and effects on biomarkers, acetylcholinesterase, glutathione-S-transferase and glutathione peroxidase, in Mytilus galloprovincialis mussel gilla. Environ. Pollut. 200, 133-139. doi: 10.1016/j.envpol.2015.02.012

White, R., Jobling, S., Hoare, S. A., Sumpter, J. P., and Parker, M. G. (1994). Environmentally persistent alkylphenolic compounds are estrogenic. Endocrinology 135, 175-182. doi: 10.1210/endo.135.1.8013351

Williams, E. T., Ehsani, M. E., Wang, X., Wang, H., Qian, Y.-W., Wrighton, S. A., et al. (2008). Effect of buffer components and carrier solvents on in vitro activity of recombinant human carboxylesterases. J. Pharmacol. Toxicol. Methods 57, 138-144. doi: 10.1016/j.vascn.2007.11.003

Ying, G. -G., Williams, B., and Kookana, R. (2002). Environmental fate of alkylphenols and alkylphenol ethoxylates-a review. Environ. Int. 28, 215-226. doi: 10.1016/S0160-4120(02)00017-X

Zhou, Y., Fu, W. B., Si, F. L., Yan, Z. T., Zhang, Y. J., He, Q. Y., et al. (2019). UDP-glycosyltransferase genes and their association and mutations associated with pyrethroid resistance in Anopheles sinensis (Diptera: Culicidae). Malar. J. 18:62. doi: 10.1186/s12936-019-2705-2

Conflict of Interest: The authors declare that the research was conducted in the absence of any commercial or financial relationships that could be construed as a potential conflict of interest.

Copyright (c) 2021 Rougée, Collier and Richmond. This is an open-access article distributed under the terms of the Creative Commons Attribution License (CC BY). The use, distribution or reproduction in other forums is permitted, provided the original author(s) and the copyright owner(s) are credited and that the original publication in this journal is cited, in accordance with accepted academic practice. No use, distribution or reproduction is permitted which does not comply with these terms. 